\title{
CHARACTERIZATIONS AND REPRESENTATIONS FOR THE DRAZIN INVERSE OF ANTI-TRIANGULAR BLOCK OPERATOR MATRICES WITH INDEX LESS THAN TWO
}

\section{Chujian Lin, Xiaoli Deng and Chunyuan Deng}

Abstract. In the 1980s, Campbell proposed a problem to find an expression of the Drazin inverse for the block matrix $\left(\begin{array}{cc}A & B \\ -I & 0\end{array}\right)$ to research on singular differential equations. In this paper, some characterizations and detail representations for the Drazin inverse of anti-triangular block operator matrices $M=\left(\begin{array}{cc}A & B \\ I & 0\end{array}\right)$ with $\operatorname{ind}(M)=1(\operatorname{resp} . \operatorname{ind}(M)=2)$ are given.

Mathematics subject classification (2020): 15A09, 47A05.

Keywords and phrases: Drazin inverse, MP inverse, block matrix, operator decomposition, index.

\section{REFERENCES}

[1] M. BARRAA, E. H. BenABDi, On equivalence of linear combinations of idempotents, Linear Multilinear Algebra 152 (2018) 38-64.

[2] A. Ben-Isral, T. N. E. Greville, Generalized Inverses: Theory and Applications, 2nd ed, Springer-Verlag, 2003.

[3] C. J. Bu, K. Z. Zhang And J. M. ZhaO, Representations of the Drazin inverse on solution of a class singular differential equations, Linear Multilinear Algebra 8 (2011) 863-877.

[4] S. L. CAMPBELL, The Drazin inverse and systems of second order linear differential equations, Linear Multilinear Algebra 14 (1983) 195-198.

[5] S. L. Campbell and C. D. Meyer, Generalized Inverse of Linear Transformations, London, Pitman, 1979.

[6] S. L. CAMPBELL, Singular systems of differential equations, London, Pitman, 1980.

[7] S. L. CAmpbell, C. D. Meyer JR And N. J. Rose, Applications of the Drazin inverse to linear systems of differential equations with singular constant coefficients, SIAM J. Appl. Math. 31 (1976) $411-425$.

[8] N. CASTRo-GonZÁlez, Additive perturbation results for the Drazin inverse, Linear Algebra Appl. 397 (2005) 279-297.

[9] N. Castro-González, E. Dopazo, Representations of the Drazin inverse for a class of block matrices, Linear Algebra Appl. 400 (2005) 253-269.

[10] N. Castro-GonzÁlez, J. J. Koliha, New additive results for the g-Drazin inverse, Proc. Roy. Soc. Edinburgh Sect. A 134 (2004) 1085-1097.

[11] J. J. Climent, M. Neumann, AND A. Sidi, A semi-iterative method for real spectrum singular linear systems with an arbitrary index, J. Comput. Appl. Math. 87 (1997) 21-38.

[12] R. E. CLINE, An application of representation of a matrix, MRC Technical Report 592 (1965).

[13] C. Y. Deng And H. K. Du, Representations of the Moore-Penrose inverse for a class of 2-by-2 block operator valued partial matrices, Linear and Multilinear Algebra 58 (2010) 15-26.

[14] C. Y. Deng And Y. M. WeI, A note on the Drazin inverse of an anti-triangular matrix, Linear Algebra Appl. 431 (2009) 1910-1922.

[15] D. S. Djordjević, Y. M. WeI, Additive results for the generalized Drazin inverse, J. Aust. Math. Soc. 73 (2002) 115-125. 
[16] R. G. Douglas, On majorization, factorization, and range inclusion of operators on Hilbert spaces, Proc. Amer. Math. Soc. 17 (1966) 413-416.

[17] R. E. HARTE, Invertibility and Singularity for Bounded Linear Operators, Marcel Dekker, New York, 1988.

[18] R. E. Hartwig, X. Z. Li And Y. M. Wei, Representations for the Drazin inverse of a $2 \times 2$ block matrix, SIAM J. Matrix Anal. Appl. 27 (2005) 757-771.

[19] R. E. Hartwig, G. R. Wang And Y. M. Wei, Some additive results on Drazin inverse, Linear Algebra Appl. 322 (2001) 207-217.

[20] L. L. HE, C. N. Song AND Q. X. XU, General exact solutions of certain second-order homogeneous algebraic differential equations, Linear Multilinear Algebra 64 (2016) 1011-1031.

[21] J. J. Koliha, A generalized Drazin inverse, Glasg. Math. J. 38 (1996) 367-381.

[22] J. J. Koliha, V. Rakočević, Continuity of the Drazin inverse II, Studia Math. 131 (1998) 167-177.

[23] P. Kunkel and V. Mehrmann, Differential-algebraic equations (Analysis and numerical solution), Zürich: European Mathematical Society Publishing House, 2006.

[24] Y. M. WeI, X. Z. LI AND F. B. BU, A perturbation bound of the Drazin inverse of a matrix by separation of simple invariant subspaces, SIAM J. Matrix Anal. Appl. 27 (2005) 72-81.

[25] Q. X. XU, C. N. Song AND X. F. LiU, General exact solutions of the second-order homogeneous algebraic differential equations, Linear Multilinear Algebra 63 (2015) 244-263.

[26] Q. X. XU, C. N. Song AND L. L. HE, Representations for the group inverse of anti-triangular block operator matrices, Linear Algebra Appl. 443 (2014) 191-203.

[27] Q. X. XU, C. N. Song AND L. L. HE, Representations for the Drazin inverse of an anti-triangular block operator matrix E with ind $(E) \leqslant 2$, Linear Multilinear Algebra 66 (2018) 1026-1045. 